\title{
Injurias a la corona: el caso Hásel ${ }^{*}$ Insult to the crown: Hásel case
}

\author{
María del Mar Moya Fuentes \\ Universidad de Alicante \\ ORCID ID 0000-0002-9002-5214 \\ mar.moya@ua.es
}

\section{Cita recomendada:}

Moya Fuentes, M. M. (2021). Injurias a la corona: el caso Hásel. Eunomía. Revista en Cultura de la Legalidad, 21, pp. 399-406

doi: https://doi.org/10.20318/eunomia.2021.6363

Recibido / received: 10/09/2021

\begin{abstract}
Resumen
La confirmación por el Tribunal Supremo de la condena impuesta por la Audiencia Nacional a Pablo Hásel por injurias a la familia real y a la policía, así como por enaltecimiento del terrorismo ha puesto de nuevo el foco del debate jurídico en cuáles son los límites penales a la libertad de expresión y opinión. En el presente trabajo se procede a analizar la sanción de los delitos de injurias a la corona en estas resoluciones a la luz de los estándares protectores de esta libertad del Tribunal Europeo de Derechos Humanos, que ya ha condenado a nuestro país en asuntos similares por vulnerar el art. $10 \mathrm{CEDH}$.
\end{abstract}

\section{Palabras clave}

Libertad de expresión, injurias a la corona, Tribunal Europeo de Derechos Humanos, art. 10 CEDH.

\begin{abstract}
The confirmation by the Supreme Court of the sentence handed down by the Audiencia Nacional to Pablo Hásel for insulting the royal family and the police, as well as for glorifying terrorism, has once again put the focus of the legal debate on the criminal limits to freedom of expression and opinion. This paper analyses the punishment of the offences of insulting the Crown in these rulings in the light of the protective standards of the European Court of Human Rights, which has already condemned Spain in similar cases for infringing art. 10 of the ECHR.

\section{Keywords}

Freedom of expression, honor, insult to the crown, European Court of Human Rights, article 10 ECHR, Hásel.
\end{abstract}

SUMARIO. 1. Introducción. 2. Delito de injurias a la corona: ¿límite a libertad de expresión? 3. Valoración crítica.

\footnotetext{
*Artículo realizado en el seno del PID2019-107974RB-100 «Derecho penal y distribución de la riqueza en la sociedad tecnológica».
} 


\section{Introducción}

El encarcelamiento meses atrás del rapero Pablo Hásel, tras la confirmación por el Tribunal Supremo (sentencia 135/2020, 7-2) de la condena impuesta por la Audiencia Nacional (sentencia $3 / 2018,2-3$ ) por un delito de injurias a la corona, otro a la policía y otro de enaltecimiento del terrorismo, ha puesto de nuevo el foco del debate jurídico sobre el siempre perenne problema de los límites penales a la libertad de expresión.

En efecto, si bien otros polémicos asuntos ya habían cuestionado con anterioridad el posible exceso de celo punitivo en la tutela de la opinión (recuérdese, a modo de ejemplo, el encarcelamiento de dos titiriteros por mostrar en un espectáculo infantil un cártel que decía "Gora Alka-ETA»; el enjuiciamiento de comentarios satíricos sobre la muerte de Carrero Blanco -caso Cassandra- u otros políticos -caso Strawberry- o la condena del también rapero Valtònyc por sus críticas a la Corona y a otras instituciones estatales), es el citado asunto el que ha dado lugar a una mayor y contundente protesta social. Ésta se tradujo en manifestaciones e importantes disturbios callejeros y, en especial, en una encendida discusión por parte de los expertos acerca de la argumentación de las sentencias condenatorias acompañadas ambas de votos particulares disidentes-y la necesidad de tutela penal de las figuras delictivas que en ellas se dirimen.

En lo que sigue se procede a realizar una breve reflexión crítica sobre la condena en estas resoluciones de las injurias a la corona a la luz de los estándares protectores de la libertad de expresión del Tribunal Europeo de Derechos Humanos, ante el que la defensa del cantante ya ha anunciado va a recurrir -tras agotar la vía judicial nacional-, y que en la última década ha sancionado en varias ocasiones a nuestro país por cercenar la libertad de expresión (art. $10 \mathrm{CEDH}$ ) de ciudadanos que han proferido precisamente comentarios críticos contra la monarquía española -Otegi Mondragón c. España (demanda 2034/07) y Stern Taulats y Roura Capellera c. España (demandas 51168/15 y 51186/15)-.

\section{Delito de injurias a la Corona: ¿límite a la libertad de expresión?}

Dentro del Capítulo XI del Título XXI del Libro II de nuestro texto penal se tipifican dos delitos de ofensas al rey, a su cónyuge, a sus ascendientes o a sus descendientes. Así, el art. 490.3 CP castiga las calumnias e injurias proferidas contra los anteriores sujetos en el ejercicio de sus funciones o con motivo u ocasión de éstas (prisión de seis meses a dos años si son graves, o multa de seis a doces meses si no lo son). De no guardar estas expresiones relación con el ejercicio del cargo serán sancionadas más levemente conforme al art. $491 \mathrm{CP}$ (multa de cuatro a veinte meses).

En el caso de autos se analizan cerca de una veintena de tweets y la letra de un rap que se completa con un vídeo con imágenes de los reyes publicados por el cantante entre 2014 y 2016 en su perfil de Twitter (@PabloHasel, con 54.000 seguidores) en los que, en líneas generales, se acusa al emérito -figura sobre el que se focalizan la mayoría de los mensajes- de múltiples delitos, entre ellos homicidio y malversación, así como de llevar a cabo una conducta no acorde con la autoridad que representa (despilfarro económico, consumo de drogas y alcohol, relaciones extramatrimoniales, negocios privados, vínculos de amistad con la monarquía saudí a la que se acusa de financiar al terrorismo islámico). A los que se añaden otros comentarios dirigidos a descalificar a la monarquía española (catalogada de banda criminal, mafiosa o medieval) y al actual rey (al que se espera sea desahuciado junto con toda su familia de parásitos), así como a criticar la tibieza de los dirigentes de 
izquierda con los reyes y a ensalzar las penurias que sufren miles de ancianos, mientras que los monarcas dan lecciones desde palacios.

Tras su valoración, tanto la Audiencia Nacional como el Tribunal Supremo consideran que estas afirmaciones colman el tipo del art. $491 \mathrm{CP}$ sobre la idea central de que en ellas el acusado no expone una crítica hacia la institución ni una reivindicación política de otra forma de Estado -como pudiera ser la republicana-, sino que se dirigen a menoscabar la imagen de la monarquía y de sus integrantes desde la imputación meramente personal, a fin de que quien accede a los mensajes adopte también una posición contraria a los mismos (incluso violenta). Luego, estas expresiones exceden del derecho a la «libertad de expresión», al no atisbarse en ellas crítica o queja política del monarca o de la institución, sino que se adentran en el ataque personal gratuito a su reputación como persona, afectando así a los aspectos íntimos de su vida privada y, en definitiva, atacando a su honorabilidad personal.

No comparto esta fundamentación jurídica por las siguientes razones:

Primera. Como acertadamente señala Dopico Gómez-Aller (2021), las anteriores resoluciones $-\mathrm{y}$ en particular la del Alto Tribunal- no realizan un análisis individualizado de la tipicidad de los mensajes, sino una valoración global de los mismos plagada de juicios pocos concretos acerca de su contenido y potencialidad lesiva. Lo que ha dado lugar a que se hayan reputado sin mayor explicación como penalmente relevantes mensajes:

a) que no se dirigen propiamente contra el rey u otros miembros de la familia real, sino a otros agentes públicos, tal y como ocurre con las críticas a los políticos de izquierda o las acusaciones a la monarquía saudí -que no al rey emérito- de financiación terrorista;

b) que carecen de la menor transcendencia penal, incluso aun cuando fueren dirigidos a una persona no pública. Este es el caso, por ejemplo, de la alusión al padecimiento de ancianos sin techo que, más allá de perseguir la controvertida comparativa de sus condiciones de vida con la de los monarcas, no encierra -a mi entender- ninguna imputación falsa de delito ni atentado contra la dignidad de nadie. Lo primero no se produce ni tan siquiera cuando se alude a la muerte del hermano del rey emérito, dado que se habla de un accidente, pero en ningún caso de que este lo haya matado.

c) que critican a la institución pública como tal. En efecto, el músico profiere descalificaciones, insultos y exabruptos con términos muy severos con los que expresa su desprecio y rechazo a la monarquía ante los hechos que esta y sus integrantes acometen, y que son objeto de debate público en los medios de comunicación -nacionales y extranjero-en aquel momento -y también ahora-. Luego no son expresiones ofensivas dirigidas contra la propia persona del rey o sus familiares, las cuales sí podrían ser ilícitas en relación a particulares (como es el caso de los calificativos «ladrón» o "mafioso de mierda» referidos al rey emérito), pero no cuando se producen -como ocurre en este caso- en el marco de una crítica a un personaje público fundamentadas en retazos de la realidad informativa.

Una libertad de crítica que, como bien señala el TEDH, ampara no sólo la información o las ideas recibidas favorablemente o consideradas inofensivas o indiferentes, sino también las que «que ofenden, chocan o perturban», pues así lo requiere el pluralismo, la tolerancia y el espíritu de apertura, sin los que no existiría una sociedad democrática (SSTDH de 7.12.1976, Handyse c. Reino Unido, y de 22.10.2007, Lindon, Otchakovsky-Laurens y July c. Francia); de modo que las 
restricciones a la libertad de expresión del discurso y el debate político apenas admite restricciones a la luz del art. 10.2 CEDH (STEDH 15.3.2011, Otegi Mondragón c. España; ideas que también suscribe nuestro Tribunal Constitucional en sus sentencias 177/2015-22-7; 112/2016, 20-6 y 35/2020, 25-2). En este sentido, el tribunal arguye además que cuando se trata de expresiones o conductas expresivas referidas a un cargo público -como es el de jefe de Estado-, los límites de la crítica admisible son más amplios que respecto de un particular, dado que el primero se expone inevitable y conscientemente a un control atento de sus hechos y gestos tanto por la prensa como por la ciudadanía (SSTEDH de 8.7.1986, Lingens c. Austria; y de 27.5.2004, Vides Aizsardzïbas Klubs c. Letonia).

Segunda. En relación precisamente con esto último el Alto Tribunal realiza una interesada interpretación -como bien resalta Dopico Gómez-Aller (2021)- de los hechos consistente en desvincular los mensajes de la crítica política a fin de no invocar la anterior jurisprudencia del TEDH y, en particular, su sentencia de 13.3.2018, Stern Taulats y Roura Capellera c. España -cuyo supuesto fáctico desglosa en su texto- para hacer hincapié en que en el presente asunto -a diferencia de aquel otrose vierten injurias directas y personales contra el rey emérito, y no sobre lo que representa la monarquía. Así, señala que el condenado «no trata de expresar una reivindicación política de otra forma de Estado, como pudiera ser la republicana», sino insultar y menospreciar a la monarquía y sus integrantes.

Este razonamiento de entrada no es admisible, en mi opinión, por una cuestión fundamental que excede con creces los objetivos de este trabajo y que es la plena identificación que realiza nuestro texto constitucional de la jefatura del Estado con la corona y la personificación de esta última en la figura del rey y de sus ascendientes y descendientes. Lo que hace que sea difícil sustentar la pretendida distinción por el anterior tribunal entre institución, titular, persona concreta y, menos aún, entre las esferas públicas o privadas de esta última (ampliamente sobre esta cuestión, Martínez Guerra, 2016). Clara muestra de esto último es que la tutela penal se dirige fundamentalmente a proteger el honor de quien ya ni siquiera es jefe de estado, tal y como es el caso del rey emérito, contra quien se dirigen la gran parte de las descalificaciones que fundamentan la condena.

Asimismo, de conformidad con los parámetros del TEDH, este argumento también se ha de rechazar, porque la libertad de crítica engloba tanto la propuesta de alternativas como la mera oposición a una institución -la monarquía- como a las personas públicas -el rey-. En efecto, como bien dice el mencionado tribunal, la crítica puede afectar a la persona misma porque «la invectiva política a menudo incide en la esfera personal» y representa «azares de la política y del libre debate de ideas, que son las garantías de una sociedad democrática» (STEDH de 8.7.1986, Lingens c. Austria). Es más, en relación a la crítica a los jefes de Estado, el tribunal ya ha declarado en varias ocasiones que: otorgarle una mayor protección mediante figuras delictivas agravadas a estos dirigentes -tal y como es el caso del art. 490.3 de nuestro texto punitivo- para tutelar su honor no es conforme al espíritu del convenio (doctrina sentada en los asuntos Colombani y otros c. Francia, de 25.6.2002; Pakdemirli c. Turquía, 22.2.2005 o Artun y Güvener c. Turquía, 26.6.2007, y reproducida en los asuntos contra nuestro país: Otegi Mondragón c. España, 15.3.2011; Jiménez Losantos c. España, de 14.6.2016, y Stern Taulats y Roura Capellera c. España, de 13.3.2018).

En efecto, si bien el tribunal considera que es totalmente legítimo que las instituciones estatales estén protegidas en su calidad de garantes del orden público institucional, entiende que la posición dominante que éstas ocupan obliga a las autoridades a demostrar contención en el uso del Derecho penal; no solo por la 
desproporción que puede suponer acudir a esta vía, sino fundamentalmente por el indeseable efecto desaliento (chilling effect) que ello puede generar en la ciudadanía (STEDH de 14.6.2016, Jiménez Losantos c. España; ideas que también suscribe nuestro Tribunal Constitucional en sus sentencias 177/2015-22-7; 112/2016, 20-6 y $35 / 2020$, 25-2). Luego, la protección penal cualificada que se pretende extender en este caso al monarca resulta contradictoria con la idea largamente sustentada por la jurisprudencia europea de que la protección de las personas públicas frente a ofensas contra el honor es menos intensa que la del resto de las personas, cuando estas se profieren en el contexto de la crítica política.

Tercera. EI TEDH admite que la imposición de una pena privativa de libertad cometida en el ámbito del discurso político es compatible con la libertad de expresión garantizada por el art. $10 \mathrm{CEDH}$ en circunstancias excepcionales, tales como cuando se hayan afectado seriamente otros derechos fundamentales con ocasión, por ejemplo, de un discurso de odio o incitación a la violencia (así, STEDH 15.3.2011, Otegi Mondragón c. España). En base a esta idea, nuestro Alto Tribunal sostiene que las expresiones proferidas por el cantante revelan un ánimo evidente de que quien acceda a sus mensajes adopte una posición contraria a la monarquía y sus integrantes, inclusive de forma violenta. Sin embargo, más allá de la legitimidad de arengar a adoptar una posición contraria a estos, no puede inferirse en ningún caso del relato de los hechos probados y del contenido de los mensajes -meros juicios de valor que alcanzaron una amplia difusión dado el elevado número de seguidores con los que aquél contaba en su perfil digital- que incitasen -ni siquiera de manera indirecta- a desarrollar una actividad violenta; lo que evidencia un exceso estilístico o, más bien un uso metafórico del término violento por parte del tribunal, carente de todo apoyo fáctico (así, Dopico Gómez-Aller, 2021). Asimismo, esta incitación a combatir la institución, tampoco puede deducirse como señala la resolución de la existencia en cerca de dos millares de tuits de los términos rey, Borbón o monarquía, dado que su mera identificación al margen del contenido de la misiva que lo incorpora resulta irrelevante. A lo que se añade que atribuir a estos conceptos por sí solos perfiles del discurso del odio, aun como aval a un pronóstico de riesgo, es una interpretación contra reo inadmisible (vid., STS 135/2020, 7-5, voto particular Magistrados Colmenero Menéndez de Luarca y Ferrer García).

Así las cosas, es evidente que nuestros tribunales -a excepción de contados votos particulares que abogan por la atipicidad de la disidencia política (vid., sentencias de la Audiencia Nacional, Sala de lo Penal, de 5 de diciembre de 2008 y de 21 de mayo de 2013) - siguen asumiendo una protección reforzada de la Corona y de su titular, al no asimilar los criterios interpretativos de la jurisprudencia del TEDH que reconducen al campo de la impunidad las críticas políticas contra aquellos. Hecho que permite aventurar una nueva condena a nuestro país por esta especial protección del honor de sus jefes de Estado, que resulta a todas luces contraria al espíritu del Convenio, tal y como ya ocurriera en los aludidos asuntos Otegi Mondragón y Stern Taulats y Roura Capellera.

\section{Valoración final}

A la vista de lo analizado es preocupante la tendencia que se observa en los últimos años en España a criminalizar las manifestaciones vertidas contra la monarquía, con lo que parece querer desalentarse todo comentario desfavorable contra la misma e imponer, en consecuencia, un pensamiento único bajo la amenaza de penas de multas y de prisión, y que han dado lugar ya a varias condenas por el Tribunal de Estrasburgo por violación del art. $10 \mathrm{CEDH}$. 
Unas condenas que no parece vayan a resultar puntuales o excepcionales, de aplicarse argumentaciones como las alegadas por los tribunales patrios en el asunto que nos ocupa, que ensalzan la superioridad de la jefatura del Estado y su incolumidad ante cualquier crítica por parte de la ciudadanía. A esto se une, además, que dada la nueva configuración del trámite de admisión del recurso de amparo, que requiere al demandante probar ahora no solo la lesión subjetiva de un derecho fundamental, sino también que esta trascienda el ámbito de sus intereses privados y presente una «especial trascendencia constitucional» (art. 50.1 LO 2/1979, de 3 de octubre, del Tribunal Constitucional), la litigiosidad ante el tribunal europeo por vulneración de derechos fundamentales como la libertad de expresión va a ser mayor. En efecto, esta exigencia está dando lugar a la inadmisión de la práctica totalidad de recursos para su revisión por el Tribunal Constitucional y está propiciando la interposición de demandas de los ciudadanos españoles ante el TEDH, a fin de obtener la declaración de la vulneración de su derecho y de su reparación, lo que consecuentemente redunda en un aumento de resoluciones que determinan que nuestro país ha vulnerado uno de los derechos del CEDH (Ripol Carulla, 2014).

Lamentable será -aventuro- el espectáculo que dé nuestra nación cuando sus cantantes, humoristas, artistas y, en definitiva, todo ciudadano disidente perseguidos por la sátira política deban ir hasta Estrasburgo para que se tomen en serio sus libertades fundamentales. Lo que me lleva a preguntarme con cierta perplejidad cuántos varapalos judiciales más deberá recibir España por parte de las instituciones europeas para acabar con esta protección irregular, obsoleta y excesiva a la monarquía, que no se ajusta a la realidad que vivimos.

A fin de evitar este desalentador escenario sería deseable, a mi juicio, que nuestros tribunales asimilasen con urgencia la jurisprudencia del TEDH en materia de libertad de expresión, apostando por una mayor tolerancia a la crítica relativa a la actuación de las autoridades estatales, limitada solo en supuestos de extrema gravedad - p. ej., incitación al odio o a la violencia-. En este sentido, devendría esencial: a) abandonar la idea de superioridad de la monarquía frente a otras instituciones democráticas; b) dejar de personificar a la corona como jefatura del Estado en su concreto titular; c) distinguir entre los ámbitos público y privado del jefe del Estado y, en base a esto último, d) limitar la tutela penal de su honor, el de su consorte, ascendientes o descendientes a los tipos comunes o a la vía civil (en esta línea, Martínez Guerra, 2016). Aunque lo realmente esperable sería que nuestro legislador abogase por renunciar a la sanción penal en materia de injurias y calumnias a la corona con la que se desincentiva la contribución del ciudadano a la discusión de cuestiones que interesan a la vida de la colectividad [también así, Corral-Maraver (2020), Presno Linero (2018) y el Grupo de Estudios de Política Criminal (2019), quien propone que las calumnias e injurias contra las instituciones del Estado se persigan de oficio a través de sus figuras genéricas conforme al art. 215.1 CP].

Estas recomendaciones ya han sido efectuadas desde el Comité de Ministros del Consejo de Europa (vid., Resolución 1577, de 4 de octubre de 2007, sobre la despenalización de la difamación y de 12 de febrero de 2004, sobre la libertad de discurso político en los medios de comunicación), que considera fundamental para garantizar la libertad del debate político que los derechos nacionales eliminen cualquier tipo de sobreprotección de las autoridades y cargos políticos -incluso cuando sus funciones sean meramente simbólicas-, así como que despenalicen los delitos de difamación y de insulto contra estos, ya que la vía penal de estas conductas no responde a medidas necesarias en una sociedad democrática. De hecho, son diversas ya las ocasiones que desde la comisaría de derechos humanos de esta organización (la última en marzo de este mismo año) se nos ha solicitado la 
introducción de cambios legales sobre las injurias a la corona en nuestro orden penal en el sentido indicado.

De momento, estas medidas únicamente se han materializado en nuestro país en un fallido intento legislativo de despenalización de las injurias y calumnias contra la corona propuesta por el Grupo Parlamentario de IU, ICV-EUiA, CHA: la Izquierda Plural (Boletín Oficial de las Cortes Generales, 122/00039, núm. 51-1, de 3 de febrero 2 de 2012), que acabo decayendo y, más recientemente, en el anuncio por parte del Ministerio de Justicia -al albur precisamente de las protestas por la condena a Hásel y a pocos días de su entrada en prisión- de una revisión de los delitos relacionados con el ejercicio de la libertad de expresión dirigida a restringir la sanción penal de aquellas conductas que supongan un claro riesgo para el orden público o la provocación a la violencia, que si bien llevarán aparejadas penas disuasorias nunca serán privativas de libertad. Con ello pretende el Ejecutivo dejar extramuros del ius puniendi los excesos verbales que se cometan en el contexto de manifestaciones artísticas, culturales o intelectuales, ya que a su juicio el Derecho penal no es la herramienta más útil, necesaria ni proporcionada para responder a comportamientos que, pese a poder rozar la ilicitud, su sanción supondría un desaliento para la libertad de expresión, conforme a lo declarado por nuestro Tribunal Constitucional y el Tribunal Europeo de Derechos Humanos.

No obstante, pese a las expectativas generadas por este anuncio, a día de hoy, el Gobierno no ha alumbrado ningún texto en esta materia. No obstante, es necesario reseñar en este sentido que el pasado mes de junio, el Grupo Parlamentario Socialista sí respaldó la tramitación de la Proposición Ley Orgánica de reforma del Código Penal para la protección de la libertad de expresión (Boletín Oficial de las Cortes Generales 122/000124, núm. 149-1, de 19 de febrero de 2021), presentada por el Grupo Parlamentario Confederal de Unidas Podemos-En Comú Podem-Galicia en Común (justamente un día después de lo anunciado por el Ministerio de Justicia) y cuyo contenido es casi idéntico a la proposición de ley que registró años atrás (Boletín Oficial de las Cortes Generales 122/000211, núm. 239-1, de 23 de marzo de 2018), pero que finalmente no salió adelante.

Esta propuesta -en trámite de enmiendas en el momento en que se escriben estas líneas- contempla, entre otras medidas, precisamente la derogación expresa del ilícito aquí analizado, a la que se suma la de los delitos de injurias a las Instituciones del Estado (art. $504 \mathrm{CP}$ ); contra los sentimientos religiosos (art. $525 \mathrm{CP}$ ) y las ofensas o ultrajes de palabra, por escrito o de hecho a España, a sus comunidades autónomas o a sus símbolos (art. $543 \mathrm{CP}$ ), así como el enaltecimiento del terrorismo, al considerar que con la aplicación de estos tipos delictivos -que califica como obsoletos y procedentes de la dictadura- se criminalizan conductas tales como críticas al rey, pitadas al himno nacional, performances feministas, letras de canciones o mensajes en redes sociales; lo que choca frontalmente con la esencia de este derecho fundamental y es inadmisible en un sistema plural y democrático como el español.

Será pues necesario esperar para saber si esta propuesta consigue fructificar, lo que sería una elogiable medida para lograr que la libertad de expresión de los ciudadanos no venga limitada por su miedo a entrar en prisión, ya que en una democracia -como es la nuestra- la única institución a proteger y preservar por encima de todas las otras es la del ejercicio de las libertades fundamentales y, entre ellas, la libertad de crítica y disidencia política. 


\section{Bibliografía}

Corral-Maraver, N. (2020). Sentencia del TEDH en el asunto Stern Taulats y Roura Capellera c. España. Reflexiones sobre el delito de injurias a la corona y el derecho a la libertad de expresión política en España. Revista General de Derecho Penal, 34, pp. 21.

Grupo de Estudios de Política Criminal (2019). Una propuesta alternativa de regulación de los delitos de expresión.

Martínez Guerra, A. (2016). Delitos contra la corona. F. J. Álvarez García (Dir.). Tratado de derecho penal español. Pate especial. IV. Delitos contra la Constitución (pp.126-130). Valencia, España: Tirant lo Blanch

Presno Linera, M. M. (2018). Crónica de una condena anunciada: el asunto Stern Taulats y Roura Capellera c. España sobre la quema de fotos del rey. Teoría y realidad constitucional, 42, pp. 539-549.

Ripol Carulla, S. (2014). Un nuevo marco de relación entre el Tribunal Constitucional y el Tribunal Europeo de Derechos Humanos. Revista Española de Derecho Internacional, vol. LXVI/1, enero-junio, pp. 28-30. Recuperado de http://redi.eneestudio.es/wp-content/uploads/2017/09/1-Santiago-Ripol_digital.pdf 